\title{
Cytotoxicity Study of Gold Nanoparticles on the Basal-Like Triple-Negative HCC-1937 Breast Cancer Cell Line
}

\author{
Christophe Massard1 ${ }^{*}$, Clémence Dubois ${ }^{2}$, Vincent Raspal1, Pierre Daumar², Yves Sibaud1, \\ Emmanuelle Mounetou'2, Mahchid Bamdad2, Oscar Komla Awitor'
}

\footnotetext{
${ }^{1}$ Université Clermont Auvergne, Institut Universitaire de Technologie, UMR 6533 CNRS/IN2P3, LPC+, Equipe Physico Chimie des Surfaces Nanostructurées, Clermont-Ferrand, France

${ }^{2}$ Université Clermont Auvergne, Institut Universitaire de Technologie, UMR INSERM 1240 Imagerie Moléculaire et Stratégies Théranostiques, Groupe "Résistance", Clermont-Ferrand, France

Email: *christophe.massard@udamail.fr
}

How to cite this paper: Massard, C., Dubois, C., Raspal, V., Daumar, P., Sibaud, Y., Mounetou, E., Bamdad, M. and Awitor, O.K. (2018) Cytotoxicity Study of Gold Nanoparticles on the Basal-Like Triple-Negative HCC-1937 Breast Cancer Cell Line. Journal of Biomaterials and Nanobiotechnology, 9 , 13-25.

https://doi.org/10.4236/jbnb.2018.91002

Received: October 9, 2017

Accepted: December 15, 2017

Published: December 18, 2017

Copyright (c) 2018 by authors and Scientific Research Publishing Inc. This work is licensed under the Creative Commons Attribution International License (CC BY 4.0).

http://creativecommons.org/licenses/by/4.0/

\section{(c) (i) Open Access}

\begin{abstract}
The Triple Negative "Basal-like" breast cancer (TNBL) tumours have a high proliferative capacity and develop a resistance phenotype associated with metastases. However, the management of TNBL carcinomas is still not standardized. Among the promising trails, gold nanoparticles could be a relevant tool for the development of a targeted treatment for this breast cancer subtype in monotherapy, associated and/or conjugated with other drugs. In this work, we report the cytotoxicity impact of gold nanoparticles wrapped in Poly-Ethylene Glycol (PEG) on the TNBL HCC-1937 breast cancer cell line. PEG-coated gold nanoparticles (PEG-Au NPs) were synthesized by a two-step method using a reduction process followed by a post-functionalization called PEGylation. PEG-Au NPs were characterized using transmission electron microscopy and X-ray diffraction. The gold content of the samples was determined using atomic absorption spectrometer. The cytotoxicity tests were performed using Sulforhodamine B survival test and resazurin viability test. PEG-Au NPs impact analysis on HCC1937 TNBL cell line showed a clear toxic action of type dose dependent and at long term. These PEGylated gold nanoparticles present a promising tool for the development of tumor-specific radiosensitizing vectors, with or without the association of other treatment strategies.
\end{abstract}

\section{Keywords}

Breast Cancer, "Basal-Like” Triple Negative, HCC-1937, Gold Nanoparticles, Cytotoxicity 


\section{Introduction}

Gold nanoparticles (GNPs) are promising candidates in the field of medicine for the treatment of illnesses such as Alzheimer's [1], vascular [2], skin [3], sclerosis [4] and cancer [5]. Gold nanoparticles exhibit tunable physical properties making them ideal for developing diagnostic tools [6] [7] [8] [9] or therapeutic treatments using photothermal effect [10]-[15]. Gold nanocomposites can also act as radiosensitizer [16] [17] [18] [19] [20] in order to avoid collateral damages induced by the use of radiotherapy. Gold nanoparticles can also be defined as theranostic tools by combining diagnostic and therapeutic actions [21] [22] [23] [24] [25]. The use of gold nanoparticles to try to cure cancer is a very active field of research. With this nanomedicine strategy, gold nanoparticles are defined to target tumorous cells and minimize side effects [26] [27], to enhance conventional therapies [28] [29] or to develop new diagnostic and therapeutic devices [30] [31]. Despite recent advances in the treatment of cancers, cancer therapy is still a great challenge for the research in nanomedicine. The Triple Negative "Basal-like" breast cancer (TNBL) tumors are particularly aggressive and of poor prognosis. They constitute $70 \%$ of the basal-like tumor subtype and $15 \%$ of all breast cancers. They are characterized by the non-expression of estrogen receptors (ER) and progesterone receptors (PR), and the absence of HER2 over-expression or ERBB-2 amplification [32] [33] [34]. TNBL tumours have a high proliferative capacity and may respond well to neoadjuvant chemotherapy or develop a resistance phenotype associated with metastases. More, due to their properties, these tumours do not respond to targeted hormonal therapies. Consequently, many targeted therapies using inhibitors of poly (ADP-ribose) polymerase (PARP) or anti-EGFR monoclonal antibodies or combined therapies like anti-EGFR monoclonal antibodies/EGFR tyrosine kinase inhibitors or chemotherapy/radiotherapy are currently in development [35] [36] [37] [38] [39]. However, the management of TNBL carcinomas is still not standardized. Among these promising trails, gold nanoparticles could be a relevant tool for the development of a targeted treatment for this breast cancer subtype in monotherapy, associated and/or conjugated with other drugs [40]. In this context, these works were focused on the cytotoxicity impact of gold nanoparticles wrapped in Poly-Ethylene Glycol (PEG), on the TNBL HCC-1937 breast cancer cell line.

\section{Experimental}

\subsection{Synthesis of PEG-Coated Gold Nanoparticles (PEG-Au NPs)}

Before the experiment, all the glassware was carefully cleaned using aqua regia (mixture of concentrated nitric and hydrochloric acid in 1:3 volume ratio) and rinsed with ultra-pure water $(18 \mathrm{M} \Omega . \mathrm{cm})$, blown dried with nitrogen and stored at $110^{\circ} \mathrm{C}$. The starting solution is obtained by dissolving the designated amount of hydrogen tetrachloroaurate (III) hydrate $\left(\mathrm{HAuCl}_{4}, \mathrm{xH}_{2} \mathrm{O}\right)$ purchased from Sigma Aldrich to reach suitable gold concentration. Gold nanoparticles in suspen- 
sion were synthesized using a two step method. First, reduction of hydrogen tetrachloroaurate (III) precursor species was carried out using sodium borohydride under vigorous stirring for 15 minutes at room temperature; gold metal nano-cores were obtained. Secondly, gold nanoparticles surface were post functionalized using thiol-terminated poly(ethylene) glycol (HS-PEG, of MW 5000 from Sigma Aldrich). After this so called PEGylation step, red ruby, stable gold nanoparticles suspensions are obtained.

\subsection{Gold Nanoparticles Characterization}

\subsubsection{Transmission Electron Microscopy (TEM)}

A Hitachi transmission electron microscope (H7650) was used for morphological characterization.

\subsubsection{X-Ray Diffraction (XRD)}

The crystalline structure of the gold nanoparticles was determined using a Bruker D2 Phaser diffractometer. The operating parameters are listed in Table 1.

\subsubsection{Atomic Absorption Spectroscopy (AAS)}

The gold content of the samples was determined using an AA 7000 atomic absorption spectrometer (Shimadzu) with gold hollow-cathode lamp. All analyses were performed at a wavelength of $242.8 \mathrm{~nm}$ using $0.7 \mathrm{~nm}$ slit width. Before the experiments, the machine was calibrated using a gold standard for AAS (Sigma Aldrich) at $1000 \mathrm{ppm}$ in $5 \% \mathrm{HCl}$. Calibration line was performed using thirteen diluted standard solutions prepared in $5 \% \mathrm{HCl}$ suitable for trace analysis and high-purity water, 18.2 $\mathrm{M} \Omega$, ranging from 0.01 to $20 \mathrm{ppm}$, respectively.

\subsection{Cell Culture}

The HCC1937 TNBL breast cancer cell line $\left(\mathrm{ATCC}^{\circledR}\right)$ was maintained in RPMI 1640 medium $\left(\right.$ Gibco $\left.^{\circledR}\right)$, supplemented with $10 \%$ decomplemented fetal calf serum and $20 \mathrm{mg} / \mathrm{mL}$ gentamycin, in $75 \mathrm{~cm}^{2}$ culture dishes $\left(\right.$ Falcon ${ }^{\circledR}$ ) at $37^{\circ} \mathrm{C}$ under $5 \% \mathrm{CO}_{2}$, according to supplier's instructions [41]. For cytotoxicity tests, cells were detached by trypsinisation, counted with the trypan blue exclusion test, and seeded in 96-well microplates (Falcon ${ }^{\circledR}$ ), at a concentration of 2000 per well in $100 \mu \mathrm{L}$ of medium. Cells were then treated with $100 \mu \mathrm{L}$ of increasing concentrations of PEG-Au NPs $(2,4,7,14$ and $25 \mu \mathrm{M})$ diluted in the culture medium, for one to seven days. Bright field microscopy observations as well as viability tests (Sulforhodamine B test and resazurin test) of treated and untreated wells allowed the determination of nanoparticles' cytotoxicity.

Table 1. Operating parameters of XRD apparatus.

\begin{tabular}{cccccc}
\hline radiation & tube voltage & tube current & $\begin{array}{c}\text { scanning range }(2 \theta) \\
\text { scanning speed }\end{array}$ & time constant & spinning speed \\
\hline $\begin{array}{c}\mathrm{CuK} \alpha 1 \\
\lambda=1.5406 \AA\end{array}$ & $30 \mathrm{kV}$ & $10 \mathrm{~mA}$ & $\begin{array}{c}30^{\circ} \text { to } 80^{\circ} \\
0.24 \%\end{array}$ & 5 seconds & $15^{\circ} / \mathrm{min}$. \\
\hline
\end{tabular}




\subsection{Cytotoxicity Tests}

\subsubsection{Sulforhodamine B Survival Test}

Sulforhodamine B (SRB) is an anionic dye that binds electrostatically to cellular proteins, reflecting indirectly the number of living cells in the wells. Its absorbance peak is at $540 \mathrm{~nm}$. After each treatment period (from Day 1 to Day 7) cells were fixed with $50 \mu \mathrm{L}$ of a $50 \%$ (weight/volume) trichloroacetic acid (TCA) solution added to each well for 1 hour at $4^{\circ} \mathrm{C}$. Plates were then washed, dried, and 50 $\mu \mathrm{L}$ of a $0.4 \%(\mathrm{w} / \mathrm{v})$ solution of SRB in $1 \%(\mathrm{v} / \mathrm{v})$ acetic acid was added to each well. After 15 minutes of incubation at room temperature, plates were washed with $1 \%$ acetic acid solution and dried. $200 \mu \mathrm{L}$ of a $10 \mathrm{mM}$ tris-base buffer solution was finally added to the wells for dye solubilisation and plates were stirred for $30 \mathrm{~min}$. The optical density (OD) of each well was determined at $540 \mathrm{~nm}$ using a microplate reader (VWR Multiskan $\mathrm{FC}^{\circledR}$ ). Cell survival ratio was calculated by the following formula: cell survival $(\%)=\left(\right.$ Mean $\left(\mathrm{OD} \lambda_{540 \mathrm{~nm}}\right)$ of treated wells/ Mean $\left(\mathrm{OD} \lambda_{540 \mathrm{~nm}}\right)$ of untreated control wells $) \times 100$.

\subsubsection{Resazurin Viability Test}

Resazurin test is a colorimetric metabolic assay based on the reduction of resazurin into resorufin by metabolically active cells. Resorufin is a fluorescent dye exhibiting a pink colouring. After a time of incubation with resazurin, the amount of resorufin formed is proportional to the number of living cells in the wells. For these experiments, after each treatment period (from Day 1 to Day 7), medium was removed from the plates and cells were incubated with $100 \mu \mathrm{L}$ of $60 \mu \mathrm{M}$ resazurin diluted in $\mathrm{PBS}^{*}$, for 4 hours. Optical density (OD) of resorufin and resazurin were measured at 570 and $620 \mathrm{~nm}$, respectively with a microplate reader (VWR Multiskan $\mathrm{FC}^{\circledR}$ ). The corrected OD of resorufin was calculated as follows: (OD reso corr $)=\left((\mathrm{OD}) \lambda_{570 \mathrm{~nm}}-(\mathrm{OD}) \lambda_{62 \mathrm{~nm}}\right.$.) Then, the percentage of cell survival was obtained with the following formula: Cell survival (\%) $=$ (Mean (OD reso corr) of treated wells/Mean (OD reso corr) of untreated control wells) $\times 100$.

The half maximal inhibitory concentration (IC50) was calculated with the following formula, IC50 $=$ EXP (LN (concentration $>50 \%$ inhibition) $-($ (signal $>50 \%$ inhibition -50$) /(\text { signal }>50 \% \text { inhibition }- \text { signal }<50 \% \text { inhibition })^{*} \mathrm{LN}$ (concentration $>50 \%$ inhibition/concentration $<50 \%$ inhibition))) (1) [42].

\subsection{Statistical Analysis}

Cytotoxicity results were expressed as means \pm standard error of $n$ independent experiments. All experiments were performed at least in triplicate and then statistically compared using a Student's t-test. Tests were two-sided and the nominal level of significance was $\left.\mathrm{p}<0.05\left(^{*}\right), \mathrm{p}<0.01{ }^{(* *}\right), \mathrm{p}<0.001\left(^{* * *}\right), \mathrm{p}<0.0001$ $\left.{ }^{* * * *}\right)$ and $\mathrm{p}<0.00001\left(^{* * * * *}\right)$.

\section{Results and Discussion}

\subsection{Gold Nanoparticles in Suspension}

The TEM images of the synthesized gold nanoparticles in suspension are shown 


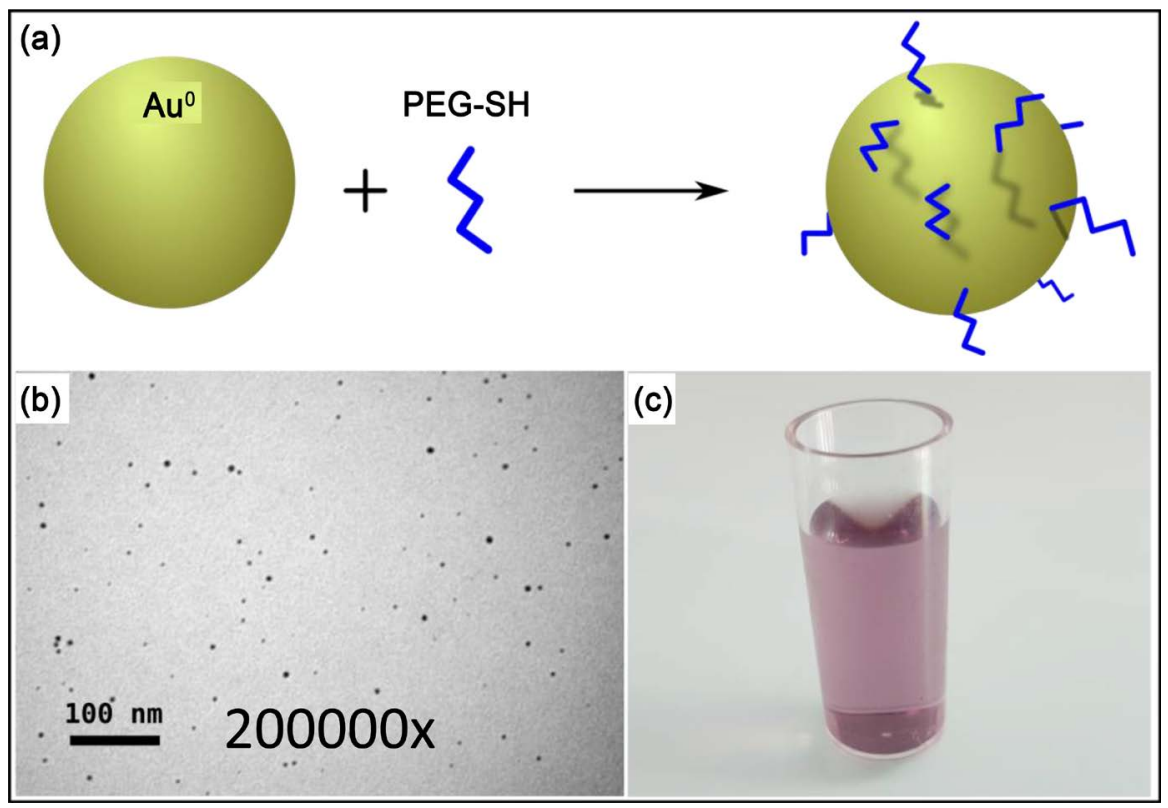

Figure 1. (a) Functionalization of Au NPs with PEG-SH; (b) High transmission electron microscopy images of PEG-coated gold nanoparticles suspensions (PEG-Au NPs); (c) Photo of PEG-coated gold nanoparticles suspensions (PEG-Au NPs) in the beaker.

\section{in Figure 1.}

(PEG-Au NPs) pictures exhibited a quasi-spherical shape, with some aggregates. Taking into account this spherical geometry, the average core diameters of PEG-coated gold nanoparticles are found to be $7 \mathrm{~nm}$. PEG-coated gold nanoparticles are synthesized using sodium borohydride as a strong reducing reagent. The PEG-coating of the gold nanoparticles, also known as pegylation, is dedicated to improve the residence in body [43] and to protect the nanoparticles from the immune system [44].

\subsection{X-Ray Diffraction Analysis}

$\mathrm{XRD}$ pattern of the analyzed gold nanopowder is presented in Figure 2. Intense peaks, relative to Bragg's reflections, could be indexed considering the face-centered cubic gold structure. No diffractions due to crystallographic impurities were found. A strong diffraction peak located at $38.7^{\circ}$ was ascribed to the (111) facets of the gold face-centered cubic structure. The other diffraction peaks relative to (200) (220) and (311) facets were much weaker. The broadening of Bragg's peaks indicates the formation of nanoparticles. The mean size of gold nanoparticles was calculated using the Debye Scherrer's equation by determining the width of the (111) Bragg reflection. The crystallite size, D, is evaluated by measuring the width of the curves produced and using the Scherrer Formula (2):

$$
D=\frac{0.9 * \lambda}{\beta \cos \theta}
$$

where $\lambda$ is the wavelength of the $\mathrm{Cu} K \alpha 1$ line in $\AA$, $\beta$ is the full-width at half max (FWHM) of the peak. The size of the crystallites was found and is approximately 


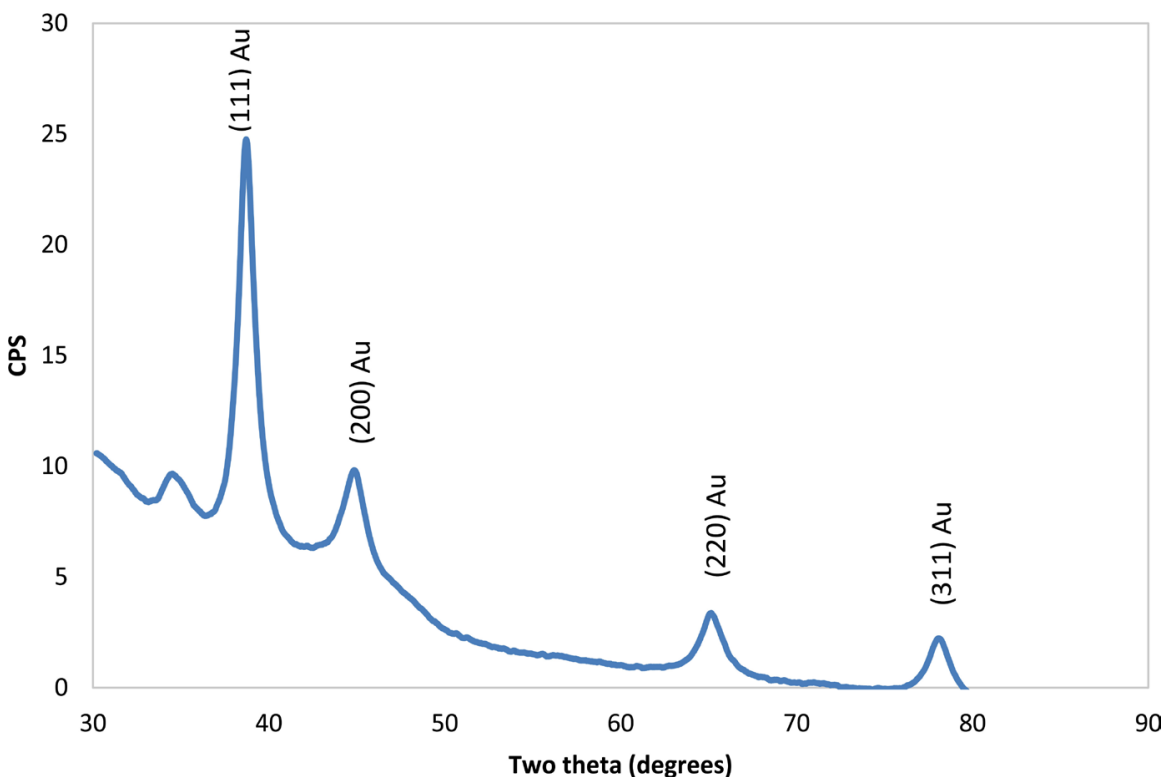

Figure 2. XRD spectrum of the gold nanopowder, the principal Bragg reflections are indexed.

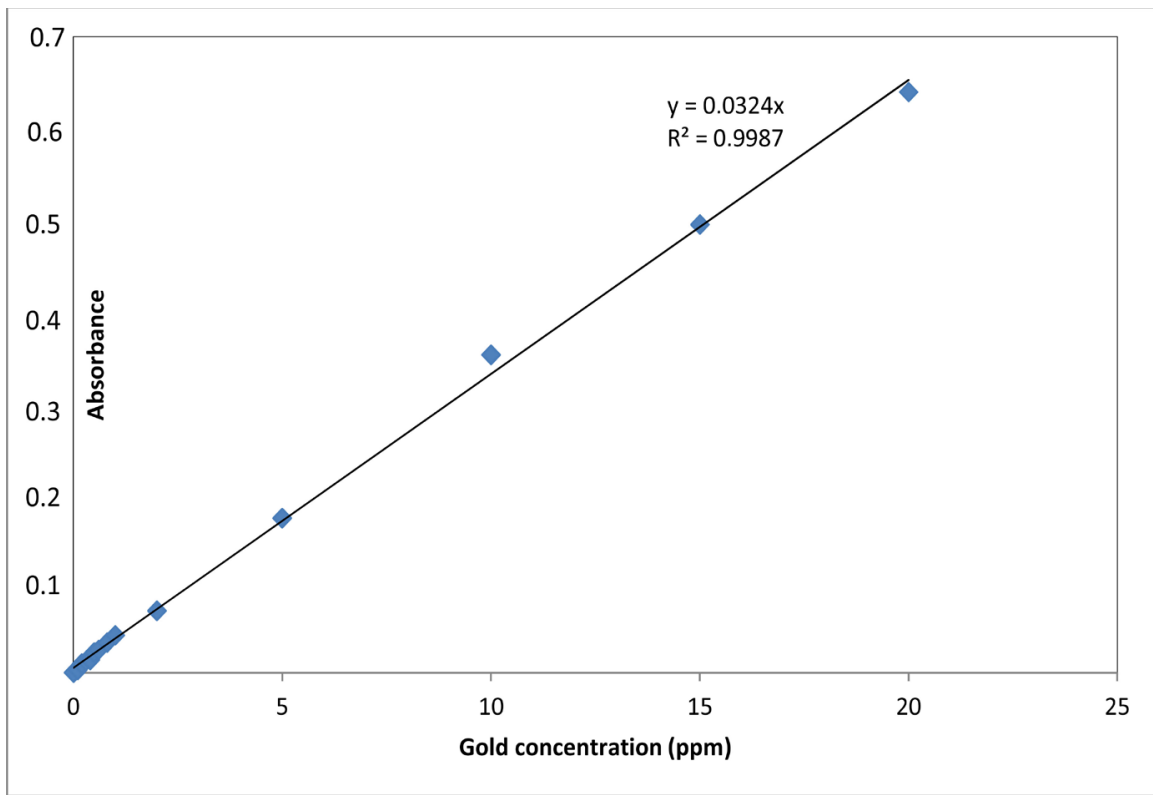

Figure 3. Calibration line was obtained by assaying thirteen diluted standard solutions ranging from 0.01 to $20 \mathrm{ppm}$, respectively.

$8 \mathrm{~nm}$ for gold nanopowder. This result is in good agreement with the average core diameter of $7 \mathrm{~nm}$ previously found.

\subsection{Atomic Absorption Spectroscopy (AAS)}

The calibration line for gold assay is presented in Figure 3. This calibration line was made by assaying thirteen diluted standard solutions ranging from 0.01 to 20 ppm, respectively. The calibration coefficient $\left(r^{2}\right)$ obtained from the calibration line was 0.9987. 
We measured the gold nanoparticles suspensions using the $5 \% \mathrm{HCl}$ solution to dilute the suspension. The gold concentration in our samples is $19.5 \mathrm{ppm}$.

\subsection{PEG-Au NPs Cytotoxicity Analysis on HCC1937 TNBL Cell Line}

The action of increasing concentrations of PEG-Au nanoparticles (2 to $25 \mu \mathrm{M}$ ) was studied on the Triple-Negative Basal-Like breast cancer cell line HCC1937, during seven days. For this, i) SRB cell survival test coupled to cell microscopy analyses and ii) cell viability via resazurin test were performed.

The rate of HCC1937 TNBL cell viability via Sulforhodamine B quantitative survival test was performed in order to quantify PEG-Au NPs toxicity on this breast cancer cell line. For this, after each treatment period, the absorbance of the Sulforhodamine B dye fixed in each well was quantified and allowed the calculation of the percentage of cell survival compared to untreated cells presented in Figure 4.

Control cells treated with PEG alone showed no difference in cell survival compared to untreated cells (data not shown). After two days of treatment with 2 and $4 \mu \mathrm{M}$ of nanoparticles, cell survival was respectively of $108 \% \pm 2 \%$ and $109 \% \pm 2 \%=$. Then, after 5 days, it decreased to $82 \% \pm 1 \%$ with $2 \mu \mathrm{M}$ and to $61 \%$ $\pm 2 \%$ with $4 \mu \mathrm{M}(\mathrm{p}<0.00001$ and $\mathrm{p}<0.00001$ respectively), and remained stable until 7 days with $85 \% \pm 1 \%$ with $2 \mu \mathrm{M},(\mathrm{p}=0.80)$ and $59 \% \pm 3 \%$ with $4 \mu \mathrm{M}(\mathrm{p}=$ 0.25). Cell survival ratio of HCC1937 cell line treated with $7 \mu \mathrm{M}$ nanoparticles was of $98 \% \pm 2 \%$ after one day of treatment, and decreased significantly to $39 \%$ $\pm 1 \%(\mathrm{p}<0.00001)$ and $28 \% \pm 2 \%(\mathrm{p}<0.00001)$ after 5 and 7 days of treatment, respectively. Then, with higher nanoparticles concentrations (14 and $25 \mu \mathrm{M})$, cell survival was of $96 \% \pm 1 \%$ and $89 \% \pm 1 \%$ after one day of treatment, and

\section{PEG-Au NPs cytotoxicity on HCC 1937 cell line} SRB test

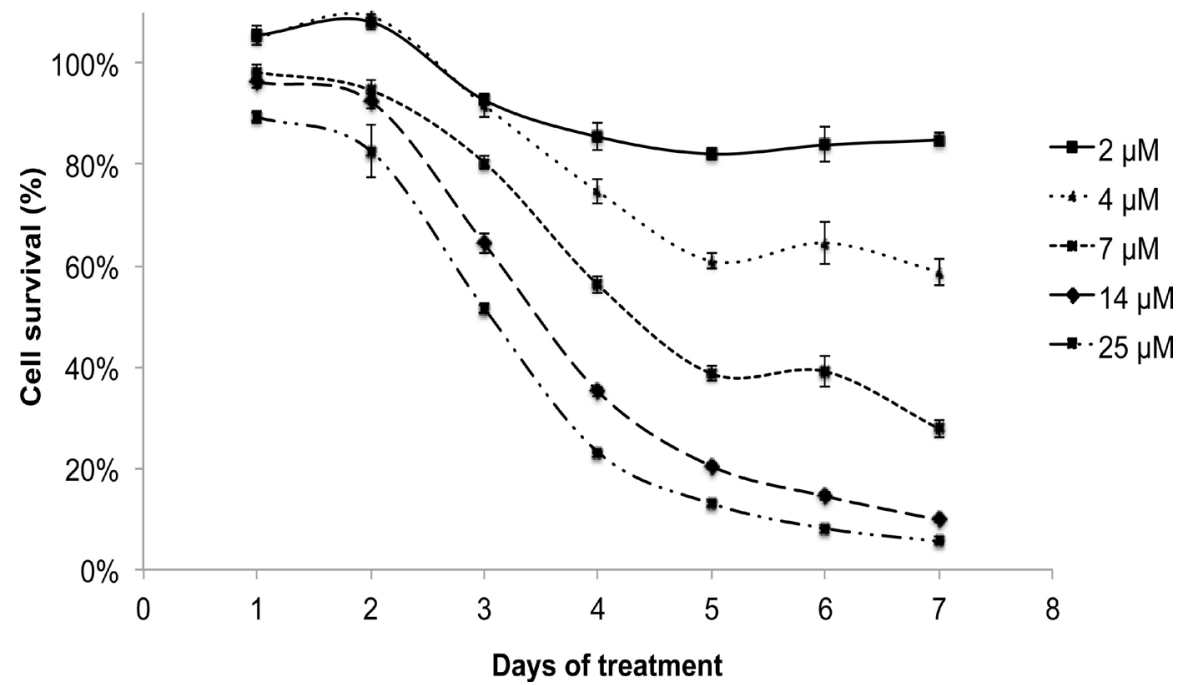

Figure 4. Mean percentage of HCC1937 cells viability determined with the Sulforhodamine B test after 1 to 7 days of treatment with increasing concentrations of PEG-Au NPs, $\left({ }^{* * * *}=\mathrm{p}<0.00001\right.$, bars on plots $=$ standard errors). 
dropped dramatically to $20 \% \pm 0.7 \%(\mathrm{p}<0.00001)$ and $13 \% \pm 0.4 \%(\mathrm{p}<0.00001)$ after 5 days of treatment. Then, it continued to decrease until 7 days of treatment, with survival rates of $10 \% \pm 0.4 \%(\mathrm{p}<0.00001)$ and $6 \% \pm 0.2 \%(\mathrm{p}<0.00001)$ for 14 and $25 \mu \mathrm{M}$ of nanoparticles, respectively. All these results showed that PEG-Au NPs toxicity on HCC1937 cell line was both dose and time-dependent. In addition, microscopy analyses presented in Figure 5 showed clearly detached cells after treatment with $25 \mu \mathrm{M}$ PEG-Au nanoparticles for seven days (Figure 5(b)) compared to controls (Figure 5(a)), in which cells have reached the confluence.

Then, the resazurin viability test involving the reduction of resazurin into resorufin by metabolically active cells was performed. The percentages of cell viability after treatment with increasing concentrations of PEG-Au NPs were calculated by the ratio of metabolic activity of untreated cells, after 1 to 7 days of treatment, see Figure 6. Similarly to SRB test, control cells with PEG alone were

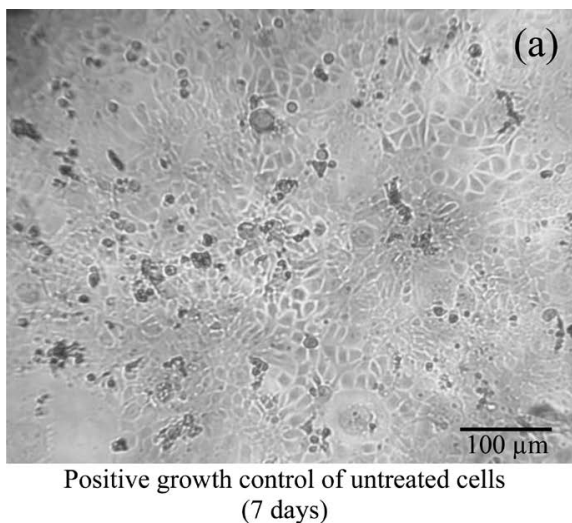

Figure 5. Bright field observations of HCC1937 cells after seven days of incubation (a) without treatment and (b) after treatment with $25 \mu \mathrm{M}$ PEG-Au NPs.

\section{PEG-Au NPs cytotoxicity on HCC 1937 cell line Resazurin test}

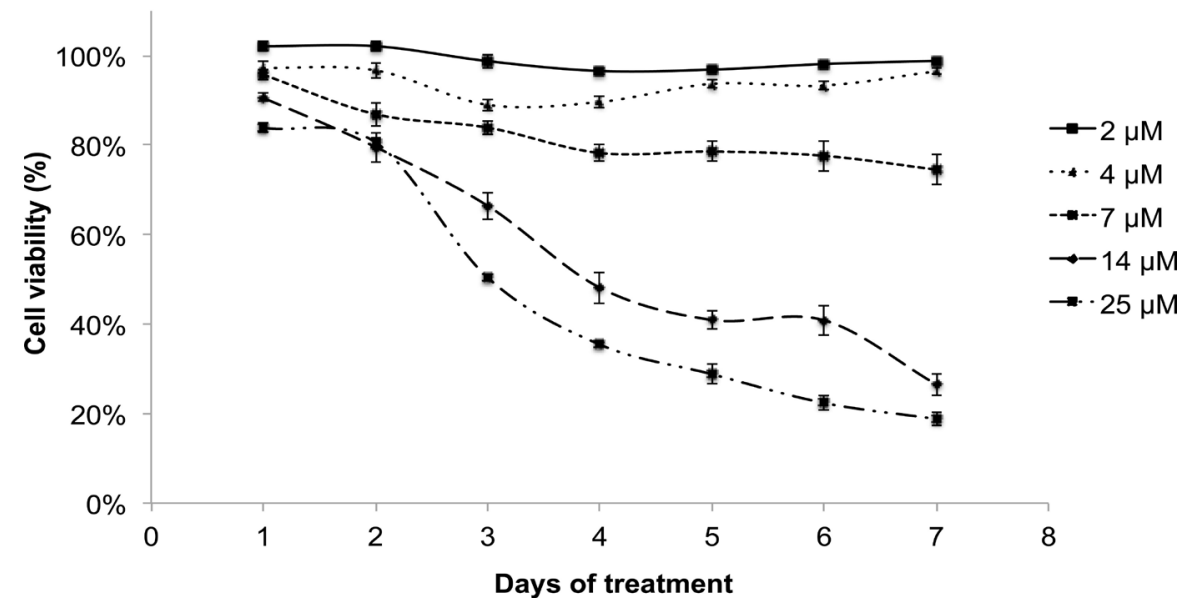

Figure 6. Mean percentage of viability of HCC1937 cells treated for 1 to 7 days with increasing concentrations of PEG-Au NPs (resazurin test), (bars on plots = standard errors). 
performed, and toxicity was not noted compared to untreated cells (Data is not shown). Then, after a treatment with $2 \mu \mathrm{M}$ of nanoparticles, cell viability was of $102 \% \pm 1 \%$ at day 1 , and remained stable until the end of the treatment with $99 \% \pm 1 \%$ at day $7(\mathrm{p}=0.28)$. A slight decrease in cell viability was detected after 3 days of treatment with $4 \mu \mathrm{M}(92 \% \pm 1 \%, \mathrm{p}<0.01)$, which remained stable until seven days $(96 \% \pm 1 \%, \mathrm{p}=0.79)$. After a treatment with $7 \mu \mathrm{M}$ of nanoparticles, cell viability was of $96 \% \pm 1 \%$ after one day, decreased significantly to $78 \% \pm 2 \%$ $(\mathrm{p}<0.00001)$ after 4 days, and remained stable until the seventh day $(75 \% \pm 3 \%$, $\mathrm{p}=0.54)$. In contrast, with a higher nanoparticles concentration of $14 \mu \mathrm{M}$, cell viability dropped from $91 \% \pm 1 \%$ after one day to $48 \% \pm 3 \%$ after 4 days ( $\mathrm{p}<$ $0.00001)$, remained relatively stable until the sixth day $(41 \% \pm 3 \%, \mathrm{p}=0.09)$ and decreased at day $7(27 \% \pm 2 \%, \mathrm{p}<0.01)$. Finally, the highest nanoparticles concentration of $25 \mu \mathrm{M}$ induced a dramatic decrease in cell viability from $84 \% \pm 1 \%$ at day 1 , to $35 \% \pm 1 \%$ at day $4(\mathrm{p}<0.00001)$, and to $19 \% \pm 2 \%$ at day 7 ( $\mathrm{p}<0.00001)$. Similarly to SRB results, these results showed a clear dose and time-dependent toxicity of PEG-Au NPs nanoparticles on HCC1937 breast cancer cell line.

\section{Discussion}

PEG-Au NPs impact analysis on HCC1937 TNBL cell line showed a clear toxic action of type dose dependent and at long term. Indeed, TNBL cells mortality increased by the time, with $\mathrm{IC}_{50}$ (SRB test) of $9 \mu \mathrm{M}$ at day 4 and of $5 \mu \mathrm{M}$ at day 7 . Similarly, $\mathrm{IC}_{50}$ (Resazurin test) was of $12 \mu \mathrm{M}$ at day 4 and decreased to $10 \mu \mathrm{M}$ at day 7. The variability between SRB survival test and resazurin viability test can be explained by a difference in sensibility thresholds due to the inner mechanism of both tests. Nevertheless, these two assays described the same toxicity profile of PEG-Au NPs nanoparticles on HCC1937 cell line, probably correlated with nanoparticles accumulation in cells.

Similarly, in previous in vitro and in vivo studies, gold nanoparticles have been used as tool both to detect and to treat breast cancer [45]. Indeed, the mostly used strategies were the ones coupling the hyperthermia effect with selective functionalization systems to optimize the cytotoxicity [46]. In general, gold nanoparticles cytotoxicity effect is mainly related to gold nanoparticle's concentration, time of exposure, and nanoparticle's size. Therefore, it would be relevant to analyse these different parameters on models of breast cancer cell cultures that mimic more faithfully the shape of tumors as 3D cell culture. Indeed, in comparison to monolayer cell culture, a systematic lowered sensitivity was detected for 3D cell culture in response to various cytotoxic drugs, probably due to $3 \mathrm{D}$ cellular heterogeneity and/or resistance phenotypes [47]. These studies are currently underway.

\section{Conclusion}

PEG-Au NPs were synthesized using a two-step method using a reduction process followed by a post-functionalization called PEGylation. Stable gold nanoparticles in suspension, suitable for biological experiments, with a gold concentration of 
$19.5 \mathrm{ppm}$, are obtained. The two cytotoxicity tests described the same PEG-Au NPs nanoparticles toxicity profile of type dose and time dependent on HCC1937 cell line, probably correlated with nanoparticles accumulation in cells. These works open the way to further experiments aiming to determine the PEG Au NPs uptake and intracellular localisation in TNBL cell line models.

\section{Acknowledgements}

The authors would like to thank the Centre Imagerie Cellulaire Santé (CICS), Université Clermont Auvergne for the electronic microscopy characterizations.

\section{References}

[1] Ali, T., Kim, M.J., Rehman, S.U., Ahmad, A. and Kim, M.O. (2016) Anthocyanin-Loaded PEG-Gold Nanoparticles Enhanced the Neuroprotection of Anthocyanins in an $\mathrm{A} \beta_{1-42}$ Mouse Model of Alzheimer's Disease. Molecular neurobiology, 54, $1-17$.

[2] Gupta, A.S. (2011) Nanomedicine Approaches in Vascular Disease: A Review. Nanomedicine: Nanotechnology, Biology and Medicine, 7, 763-779.

[3] Prow, T., Dang, N., Nufer, K., Payne, L., Soyer, H.P. and Foote, M. (2016) New Approach of Gold Nanoparticles for Treating Skin Disease. Journal of Dermatological Science, 84, e125. https://doi.org/10.1016/j.jdermsci.2016.08.374

[4] Ankri, R., Leshem-Lev, D., Lev, E.I., Motiei, M., Hochhauser, E. and Fixler, D. (2016) Gold Nanoparticles Based Imaging Technique and Drug Delivery for the Detection and Treatment of Atherosclerotic Vascular Disease. International Society for Optics and Photonics, 9721, Article ID: 97210F.

[5] Abadeer, N.S. and Murphy, C.J. (2016) Recent Progress in Cancer Thermal Therapy Using Gold Nanoparticles. The Journal of Physical Chemistry C, 120, 4691-4716. https://doi.org/10.1021/acs.jpcc.5b11232

[6] Baptista, P., Pereira, E., Eaton, P., Doria, G., Miranda, A., Gomes, I. and Franco, R. (2008) Gold Nanoparticles for the Development of Clinical Diagnosis Methods. Analytical and Bioanalytical Chemistry, 391, 943-950.

https://doi.org/10.1007/s00216-007-1768-z

[7] Kah, J.C.Y., Kho, K.W., Lee, C.G.L. and Richard, C.J. (2007) Early Diagnosis of Oral Cancer Based on the Surface Plasmon Resonance of Gold Nanoparticles. International Journal of Nanomedicine, 2, 785.

[8] Hou, W., Xia, F., Alfranca, G., Yan, H., Zhi, X., Liu, Y. and Cui, D. (2017) Nanoparticles for Multi-Modality Cancer Diagnosis: Simple Protocol for Self-Assembly of Gold Nanoclusters Mediated by Gadolinium Ions. Biomaterials, 120, 103-114. https://doi.org/10.1016/j.biomaterials.2016.12.027

[9] Tan, Y., Yan, B., Xue, L., Li, Y., Luo, X. and Ji, P. (2017) Surface-Enhanced Raman Spectroscopy of Blood Serum Based on Gold Nanoparticles for the Diagnosis of the Oral Squamous Cell Carcinoma. Lipids in Health and Disease, 16, 73. https://doi.org/10.1186/s12944-017-0465-y

[10] Cheng, X., Sun, R., Yin, L., Chai, Z., Shi, H. and Gao, M. (2017) Light-Triggered Assembly of Gold Nanoparticles for Photothermal Therapy and Photoacoustic Imaging of Tumors in Vivo. Advanced Materials, 29, 6.

[11] Cabana, S., Lecona-Vargas, C.S., Meléndez-Ortiz, H.I., Contreras-García, A., Barbosa, S., Taboada, P. and Alvarez-Lorenzo, C. (2017) Silicone Rubber Films Func- 
tionalized with Poly (Acrylic Acid) Nanobrushes for Immobilization of Gold Nanoparticles and Photothermal Therapy. Journal of Drug Delivery Science and Technology, 42, 245-254. https://doi.org/10.1016/j.jddst.2017.04.006

[12] Rajkumar, S. and Prabaharan, M. (2017) Theranostics Based on Iron Oxide and Gold Nanoparticles for Imaging-Guided Photothermal and Photodynamic Therapy of Cancer. Current Topics in Medicinal Chemistry, 17, 1858-1871. https://doi.org/10.2174/1568026617666161122120537

[13] Neshastehriz, A., Tabei, M., Maleki, S., Eynali, S. and Shakeri-Zadeh, A. (2017) Photothermal Therapy Using Folate Conjugated Gold Nanoparticles Enhances the Effects of 6MV X-Ray on Mouth Epidermal Carcinoma Cells. Journal of Photochemistry and Photobiology B: Biology, 172, 52-60. https://doi.org/10.1016/j.jphotobiol.2017.05.012

[14] Zhang, M., Kim, H.S., Jin, T. and Moon, W.K. (2017) Near-Infrared Photothermal Therapy Using EGFR-Targeted Gold Nanoparticles Increases Autophagic Cell Death in Breast Cancer. Journal of Photochemistry and Photobiology B: Biology, 170, 58-64. https://doi.org/10.1016/j.jphotobiol.2017.03.025

[15] Bucharskaya, A.B., Maslyakova, G.N., Navolokin, N.A., Terentyuk, G.S., Khlebtsov, B.N., Khlebtsov, N.G. and Tuchin, V.V. (2017) The Assesment of Effectiveness of Plasmonic Resonance Photothermal Therapy in Tumor-Bearing Rats after Multiple Intravenous Administration of Gold Nanorods. International Society for Optics and Photonics, 10336, Article ID: 103360Q.

[16] Sung, W., Ye, S.J., McNamara, A.L., McMahon, S.J., Hainfeld, J., Shin, J., et al. (2017) Dependence of Gold Nanoparticle Radiosensitization on Cell Geometry. Nanoscale, 9, 5843-5853. https://doi.org/10.1039/C7NR01024A

[17] Rosa, S., Connolly, C., Schettino, G., Butterworth, K.T. and Prise, K.M. (2017) Biological Mechanisms of Gold Nanoparticle Radiosensitization. Cancer Nanotechnology, 8, 2. https://doi.org/10.1186/s12645-017-0026-0

[18] Al Zaki, A., Cormode, D., Tsourkas, A. and Dorsey, J.F. (2017) Increasing the Therapeutic Efficacy of Radiotherapy Using Nanoparticles. In: Tofilon, P. and Camphausen, K., Eds., Increasing the Therapeutic Ratio of Radiotherapy, Humana Press, Cham, 241-265. https://doi.org/10.1007/978-3-319-40854-5_10

[19] Mulgaonkar, A., Moeendarbari, S., Silvers, W., Hassan, G., Sun, X., Hao, Y. and Mao, W. (2017) Hollow Gold Nanoparticles as Efficient in Vivo Radiosensitizing Agents for Radiation Therapy of Breast Cancer. Journal of Biomedical Nanotechnology, 13, 566-574. https://doi.org/10.1166/jbn.2017.2367

[20] Ma, N., Wu, F.G., Zhang, X., Jiang, Y.W., Jia, H.R., Wang, H.Y., et al. (2017) Shape-Dependent Radiosensitization Effect of Gold Nanostructures in Cancer Radiotherapy: Comparison of Gold Nanoparticles, Nanospikes, and Nanorods. ACS Applied Materials \& Interfaces, 9, 13037-13048. https://doi.org/10.1021/acsami.7b01112

[21] Kumar, R., Ngwa, W., Joshi, V., Kunjachan, S., Berbeco, R., Makrigiorgos, M. and Sridhar, S. (2017) Abstract B41: Gold Nanoparticles Based Platforms for Localized Radiosensitization in Cancer Radiation Therapy. Cancer Research, 77, B41. https://doi.org/10.1158/1538-7445.EPSO16-B41

[22] Ferrero, V., Visonà, G., Dalmasso, F., Gobbato, A., Cerello, P., Strigari, L., et al. (2017) Targeted Dose Enhancement in Radiotherapy for Breast Cancer Using Gold Nanoparticles, Part 1: A Radiobiological Model Study. Medical Physics, 44, 1983 1992. https://doi.org/10.1002/mp.12180

[23] Saberi, A., Shahbazi-Gahrouei, D., Abbasian, M., Fesharaki, M., Baharlouei, A. and 
Arab-Bafrani, Z. (2017) Gold Nanoparticles in Combination with Megavoltage Radiation Energy Increased Radiosensitization and Apoptosis in Colon Cancer HT-29 Cells. International Journal of Radiation Biology, 93, 315-323. https://doi.org/10.1080/09553002.2017.1242816

[24] Soleymanifard, S., Rostami, A., Aledavood, S.A., Matin, M.M. and Sazgarnia, A. (2017) Increased Radiotoxicity in Two Cancerous Cell Lines Irradiated by Low and High Energy Photons in the Presence of Thio-Glucose Bound Gold Nanoparticles. International Journal of Radiation Biology, 93, 407-415. https://doi.org/10.1080/09553002.2017.1268282

[25] Gadoue, S.M., Toomeh, D., Zygmanski, P. and Sajo, E. (2017) Angular Dose Anisotropy around Gold Nanoparticles Exposed to X-Rays. Nanomedicine: Nanotechnology, Biology and Medicine, 13, 1653-1661. https://doi.org/10.1016/j.nano.2017.02.017

[26] Patra, C.R., Bhattacharya, R., Mukhopadhyay, D. and Mukherjee, P. (2010) Fabrication of Gold Nanoparticles for Targeted Therapy in Pancreatic Cancer. Advanced Drug Delivery Reviews, 62, 346-361. https://doi.org/10.1016/j.addr.2009.11.007

[27] Reuveni, T., Motiei, M., Romman, Z., Popovtzer, A. and Popovtzer, R. (2011) Targeted Gold Nanoparticles Enable Molecular CT Imaging of Cancer: An in Vivo Study. International Journal of Nanomedicine, 6, 2859-2864.

[28] Hainfeld, J.F., Slatkin, D.N. and Smilowitz, H.M. (2004) The Use of Gold Nanoparticles to Enhance Radiotherapy in Mice. Physics in Medicine and Biology, 49, N309. https://doi.org/10.1088/0031-9155/49/18/N03

[29] Chang, M.Y., Shiau, A.L., Chen, Y.H., Chang, C.J., Chen, H.H.W. and Wu, C.L. (2008) Increased Apoptotic Potential and Dose-Enhancing Effect of Gold Nanoparticles in Combination with Single-Dose Clinical Electron Beams on Tumor-Bearing Mice. Cancer Science, 99, 1479-1484. https://doi.org/10.1111/j.1349-7006.2008.00827.x

[30] Letfullin, R.R., Joenathan, C., George, T.F. and Zharov, V.P. (2006) Laser-Induced Explosion of Gold Nanoparticles: Potential Role for Nanophotothermolysis of Cancer. Nanomedicine, 1, 473-480. https://doi.org/10.2217/17435889.1.4.473

[31] von Maltzahn, G., Park, J.H., Agrawal, A., Bandaru, N.K., Das, S.K., Sailor, M.J. and Bhatia, S.N. (2009) Computationally Guided Photothermal Tumor Therapy Using Long-Circulating Gold Nanorod Antennas. Cancer Research, 69, 3892-3900. https://doi.org/10.1158/0008-5472.CAN-08-4242

[32] Anders, C.K. and Carey, L.A. (2009) Biology, Metastatic Patterns, and Treatment of Patients with Triple-Negative Breast Cancer. Clinical Breast Cancer, 9, S73-S81. https://doi.org/10.3816/CBC.2009.s.008

[33] Prat, A. and Perou, C.M. (2011) Deconstructing the Molecular Portraits of Breast Cancer. Molecular Oncology, 5, 5-23. https://doi.org/10.1016/j.molonc.2010.11.003

[34] Banda, M., Speyer, C.L., Semma, S.N., Osuala, K.O., Kounalakis, N., Torres Torres, K.E., Barnard, N.J., Kim, H.J., Sloane, B.F., Miller, F.R., Goydos, J.S. and Gorski, D.H. (2014) Metabotropic Glutamate Receptor-1 Contributes to Progression in Triple Negative Breast Cancer. PLoS ONE, 9, e81126. https://doi.org/10.1371/journal.pone.0081126

[35] Dufy, M.J., McGowan, P.M. and Crown, J. (2012) Targeted Therapy for Triple-Negative Breast Cancer: Where Are We? International Journal of Cancer, 131, 2471-2477. https://doi.org/10.1002/ijc.27632

[36] Dufour, R., Daumar, P., Mounetou, E., Aubel, C., Kwiatkowski, F., Abrial, C., Vatoux, C., Penault-Llorca, F. and Bamdad, M. (2015) BCRP and P-gp Relay Overex- 
pression in Triple Negative Basal-Like Breast Cancer Cell Line: A Prospective Role in Resistance to Olaparib. Scientific Reports, 5, Article No. 12670. https://doi.org/10.1038/srep12670

[37] El Guerrab, A., Bamdad, M., Bignon, Y.J., Penault-Llorca, F. and Aubel, C. (2017) Anti-EGFR Monoclonal Antibodies Enhance Sensitivity to DNA-Damaging Agents in BRCA1-Mutated and PTEN-Wild-Type Triple-Negative Breast Cancer Cells. Molecular Carcinogenesis, 56, 1383-1394. https://doi.org/10.1002/mc.22596

[38] El Guerrab, A., Bamdad, M., Kwiatkowski, F., Bignon, Y.J., Penault-Llorca, F. and Aubel, C. (2016) Anti-EGFR Monoclonal Antibodies and EGFR Tyrosine Kinase Inhibitors as Combination Therapy for Triple-Negative Breast Cancer. Oncotarget, 7, 73618-73637.

[39] Gani, C., Coackley, C., Kumareswaran, R., Schütze, C., Krause, M., Zafarana, G. and Bristow, R.G. (2015) In Vivo Studies of the PARP Inhibitor, AZD-2281, in Combination with Fractionated Radiotherapy: An Exploration of the Therapeutic Ratio. Radiotherapy and Oncology, 116, 486-494. https://doi.org/10.1016/j.radonc.2015.08.003

[40] Lee, J., Chatterjee, D.K., Lee, M.H. and Krishnan, S. (2014) Gold Nanoparticles in Breast Cancer Treatment: Promise and Potential Pitfalls. Cancer Letters, 347, 46-53. https://doi.org/10.1016/j.canlet.2014.02.006

[41] Clémence, D., Robin, D., Pierre, D., Corinne, A., Claire, S., Christelle, B., Emmanuelle, M., Frédérique, P.-L. and Bamdad, M. (2017) Development and Cytotoxic Response of Two Proliferative MDA-MB-231 and Non-Proliferative SUM1315 ThreeDimensional Cell Culture Models of Triple-Negative Basal-Like Breast Cancer Cell Lines. Oncotarget, 8, 95316-95331.

[42] University of Antwerp (2010) KALADRUG-R: Laboratory SOP\#18. Simple Method and Tool for Calculation IC50-Values.

http://www.leishrisk.net/leishrisk/userfiles/file/kaladrug-r/sops/lab/labsop18_ic50to ol.pdf

[43] Veronese, F.M. and Pasut, G. (2005) PEGylation, Successful Approach to Drug Delivery. Drug Discovery Today, 10, 1451-1458. https://doi.org/10.1016/S1359-6446(05)03575-0

[44] Jokerst, J.V., Lobovkina, T., Zare, R.N. and Gambhir, S.S. (2011) Nanoparticle PEGylation for Imaging and Therapy. Nanomedicine, 6, 715-728.

https://doi.org/10.2217/nnm.11.19

[45] Ghaznavi, H., et al. (2017) Folic Acid Conjugated PEG Coated Gold-Iron Oxide Core-Shell Nanocomplex as a Potential Agent for Targeted Photothermal Therapy of Cancer. Artificial Cells, Nanomedicine, and Biotechnology, 1-11. https://doi.org/10.1080/21691401.2017.1384384

[46] Ong, Z.Y., et al. (2017) Multibranched Gold Nanoparticles with Intrinsic LAT-1 Targeting Capabilities for Selective Photothermal Therapy of Breast Cancer. ACS Applied Materials \& Interfaces, 9, 39259-39270. https://doi.org/10.1021/acsami.7b14851

[47] Huang, K.Y., Ma, H.L., Liu, J., et al. (2012) Size-Dependent Localization and Penetration of Ultrasmall Gold Nanoparticles in Cancer Cells, Multicellular Spheroids, and Tumors in Vivo. ACS Nano, 6, 4483-4493. https://doi.org/10.1021/nn301282m 